\title{
The Passive Voice
}

\author{
Richard B. Gunderman and Laura A. Steinmeyer \\ Indiana University School of Medicine, 702 North Barnhill Drive, Room 1053, Indianapolis, IN 46202
}

Key Words: Passive voice; radiologists; radiology; communication

In our anecdotal experience, radiological discourse-particularly the written form-is filled with the passive voice. "There is a nodule in the lateral segment of the right lower lobe that is thought to be..." "A total of 35 cases were included in the series." "The data were analyzed using...” “The catheter was then exchanged over the wire.” Particularly, in the domains of research publications and the reporting of radiologic procedures, the passive voice appears to dominate.

Yet authorities on writing repeatedly warn against the use of the passive voice, saying that it almost always degrades the quality of writing and speaking. Says William Strunk, the author of one of the 20th century's writers' bibles, The Elements of Style, “The active voice is usually more direct and vigorous than the passive.” (1). The Columbia Guide to Standard American English states, "If you want your words to seem impersonal, indirect, and noncommittal, passive is the choice.” (2). One of the 20th century's greatest writers, George Orwell, writes "Never use the passive voice when you can use the active.” (3).

So why, then, is the passive voice so prevalent in the writing of radiologists? In what follows, we briefly outline the meaning of the passive voice, review the history of its use in scientific and medical writing, and examine the arguments for and against it. We believe that many of the radiologists who opt for the

This is the author's manuscript of the article published in final edited form as:

Gunderman, R. B., \& Steinmeyer, L. A. (2015). The Passive Voice. Academic Radiology, 22(9), $1206-1207$.

http://doi.org/10.1016/j.acra.2015.03.019 
passive voice do so out of sheer habit, and not as the result of any conscious deliberation on the matter, and we argue that the quality of writing in radiology-and by extension, the quality of thinking in the field-could be improved by shifting the balance toward greater reliance on active voice.

In a sentence written in the active voice, the subject is the actor. In a passive voice sentence, the subject is acted on. For example, "I explained the procedure and its benefits, risks, and alternatives to the patient and obtained informed consent" is in active voice, whereas "the procedure, its benefits, risks, and alternatives were explained to the patient” is in the passive voice. As in the latter case, it is quite common in radiology writing to omit the subject altogether, leaving it uncertain who performed a particular action.

One simple clue that a writer is using the passive voice is the presence of a variation of the verb "to be" in the verb phrase. Examples include am, is, are, were, been, and so forth. Of course, this is not true in every case, but it is suggestive. Another clue is the presence of prepositional phrases using words such as "by," as in "action x was performed by agent y."

Many good writers and English instructors warn against the use of the passive voice because it tends to make sentences seem awkward, flat, and unengaging. In scientific discourse up to the end of the 19th century, writers actually tended to prefer the active voice (4). At that time, the concept of scientific rationality grew increasingly influential, and so the passive voice, which was seen as more objective, began to replace the active (4). Instead of saying that the experimenter or physician did something or thought something was a good idea, the writer could simply say that something was done, or that a particular course of action "was indicated." This makes it sound as though had anyone else done it or examined the situation carefully, the result would have been the same.

Interestingly, many recent scientific writing guides advocate the use of the active voice, but scientific literature has been slow to change (5). As we have said, today the passive voice is everywhere. One recent 
study of the medical literature suggested that the passive voice is found in up to $26 \%$ of sentences in the medical writing, whereas the corresponding figure for the Wall Street Journal is only 3\% (5). Another possible rationale for the pandemic of passive voice in medical writing is that writers are attemptingconsciously or unconsciously-to de-emphasize the agent and focus attention on the patient (6). In many cases, writers may simply assume that the identity of the agent is understood, and what is really interesting about the narrative is the particular procedure, equipment, or supplies that the agent chose to use in the patient's care.

In some cases, the use of the passive voice may reflect a reluctance to use personal pronouns over and over again in recounting story (5). For example, “First I...Then I...After which I...And finally I...” The same could be said for notes in which another agent's actions are being described, such as a procedure largely performed by a person other than the one writing the note. However, adopting this approach can easily obscure a reader's understanding of who did what, when multiple agents are involved.

In some cases, this may be precisely the point. By leaving themselves out of the story, some radiologists may hope to diminish their own responsibility-potential or actual-for what was done. Consider a procedure in which an error was made. This could be an error regarding whether the procedure was indicated, a flawed technique, an error in equipment selection, or any number of other mistakes. In many cases, those reporting such a procedure may find the use of the passive voice particularly attractive, making it sound as though events simply transpired, and downplaying the fact that any particular person was making choices or actively doing them. Knowing that errors are not always recognized at the time of a procedure, some radiologists may find it attractive to compose all such reports in the passive voice.

Although this is a questionable reason for writing in the passive voice, we believe there is a still worse one: the fact that nearly everyone seems always to have done it this way (5). In too many cases, we are habituating learners to the use of the passive voice for no good reason. If we are going to persist in its use, 
we should at the very least have a sound rationale for doing so, and at some point, we should alert learners to the reasons behind it. Otherwise, we are simply taking another generation of very smart people and undermining their capacity to write-and by extension, to think-well.

The active voice is generally more straightforward, easier to understand, and less ambiguous than the passive voice (7). Rudolf Flesch, an authority on English literacy says, "If you want to write well, about anything at all, you must be prepared to face the consequences and portray yourself quite mercilessly whenever the occasion arises.” (8). A handbook of medical writing states, "Formal, unassertive language does not make a work scholarly. Nor does it make it scientific. It just makes it lifeless and vague.” (9).

Although this is not to say that the presence of the passive voice in radiology writing should be treated like a cancer, it does imply that radiologists who care about the quality of radiologic discourse should generally avoid and discourage its use.

Consider a phrase that has become ubiquitous in contemporary discourse, particularly in settings such as corporate board rooms, congressional hearings, and press briefings: “Mistakes were made.” People who utter or write such vile phrases are neither admitting which specific decisions or actions constituted errors nor acknowledging the identity of those responsible. The account is framed in an entirely abstract way, using a word that implicitly denies any intent on the part of the agents. A political scientist has even gone so far as to suggest that this represents a new grammatical form, which he refers to as the "past exonerative.” (10). William Safire referred to the same phenomenon as the "passive-evasive” voice (11).

In sum, those who care about the quality of writing and thinking in radiology have good reason to reexamine the unreflective and uncritical use of the passive voice. Our goal in this article has been not to demonize it, but to suggest that promulgating its use either for no reason or for ultimately unworthy reasons is not doing the field any good and may in fact be taking an unnecessary toll on it. 


\section{References}

1. Strunk W. The elements of style. Geneva, N.Y.: Press of W.P. Humphrey. Bartleby.com, 1999, www.bartleby.com/141/; 1918. Accessed March 17, 2015.

2. Wilson K. The Columbia guide to standard American English. New York City, NY: Columbia University Press, 1993.

3. Orwell G. “'Politics and the English language’’. London: Horizon, 1946.

4. Ding D. Rationality reborn: historical roots of the passive voice in scientific discourse. In: Battalio JT, ed. Essays in the study of scientific discourse: methods, practice, and pedagogy. Stamford, CT: Ablex Publishing Corporation, 1998; 117-135.

5. Amdur RJ, Kirwan J, Morris CG. Use of the passive voice in medical journal articles. AMWA Journal 2010; 25:98-104.

6. Porter K. The frequency and function of passive voice use in nurses' notes. University of North Carolina at Wilmington, 2005.

7. Sheffield N. Passive voice in scientific writing. Available at: https://cgi.duke.edu/web/sciwriting/index.php?action=passive_voice Accessed March 19, 2015.

8. Flesch R. How to write, speak, and think more effectively. New York: Harper, 1960.

9. Sheen AP. Breathing life into medical writing: a handbook. St. Louis: Mosby, 1982.

10. Broder JM. “Familiar fallback for officials: 'mistakes were made’’’. The New York Times, 2007-0313.

11. Safire W. Safire’s political dictionary. New York City, NY: Oxford University Press, 2008; 431. 